\section{Reducing intraocular pressure: is surgery better than drugs?}

T Shaarawy ${ }^{1,2}$, J Flammer ${ }^{2}$ and IO Haefliger ${ }^{2}$

nervous system degeneration, or means of regenerating lost neurones.

After more than a century of active research in the management of glaucoma, the 'Holy Grail' of glaucoma treatment is still elusive, and we have to be pragmatically content with our attempts to prevent further progression of glaucomatous damage, rather than curing the disease.

Glaucoma progression is strongly associated with a number of risk factors. ${ }^{7-14}$ Some of these factors are unmanageable like ethnicity and age, while others can be manipulated, with varying degrees of success, in an attempt to slow or arrest progression, like intraocular pressure (IOP) and possibly vascular dysregulation.

Reducing IOP is presently the evidencebased, most accepted, and most practised therapeutical approach of glaucoma patients. ${ }^{12,15,16}$

Currently, topical ocular hypotensive medications, with its different classes, as well as filtering surgery (trabeculectomy and nonpenetrating surgery) are in the forefront of therapeutic modalities to reduce IOP. ${ }^{15,17-23}$

This review article looks at the potential advantages and disadvantages of topical medications $v s$ filtering surgery and vice versa. It does not directly address the question of initial treatment of glaucoma, ${ }^{20,21,24-29}$ or what is the better treatment 30 of glaucoma, as other review articles had, but rather looks in a more specific fashion on the pros and cons of each in relation to IOP reduction. In other words, this review article deals with the situation once the decision has been made to reduce IOP.

\section{What is the ideal treatment to reduce IOP?}

Based on available knowledge, ${ }^{12,15,18,23,24,28,30}$ an ideal treatment to reduce IOP should achieve different objectives. It should offer sufficient reduction in IOP, possibly in the low teens. It
${ }^{1}$ Glaucoma Unit Memorial Research Institute of Ophthalmology, Giza, Egypt

${ }^{2}$ Basel University Eye Clinic Basel, Switzerland

Correspondence: T Shaarawy, MD Glaucoma Surgery Research Group

University Eye Hospital Mittlere St. 91 Basel 4012 Switzerland

Tel: + 41612658781

Fax +41612658652

E-mail: shaarawy@ glaucoma-surgery.com

Received: 10 April 2003 Accepted: 5 November 2003

Published online: 16 April 2004 degeneration of retinal ganglion cells, and to date there is no cure for neuronal central 
should provide this reduction on a long-term bases and not just momentarily or sporadically. It should be associated with minimal IOP fluctuation, IOP fluctuation being identified as a significant and independent risk factor.

It should, if possible, encourage patient compliance or, better still, be totally independent from the compliance factor. On top of all that the ideal treatment should offer tolerable systemic and local side effects, or again better still be devoid of side effects.

Last but by any means not least, in a world exceedingly aware of the heavy medical care expenses, ${ }^{31}$ an ideal treatment to reduce IOP should be economically sound.

\section{Sufficient reduction of IOP}

Although it has been suggested that IOP reduction should be individualised to specific target pressure ${ }^{32}$ for each specific patient, in the majority of our patients, we are mostly aiming at pressures in the low teens. ${ }^{33}$

In. the Advanced Glaucoma Intervention Study (AGIS), ${ }^{33}$ eyes were randomised to laser trabeculoplasty or filtering surgery when medical therapy failed. In the roughly one quarter of eyes in the study in which the IOP was always lower than $18 \mathrm{mmHg}$ (mean IOP, $12.3 \mathrm{mmHg}$ ) during 6 years of follow-up, there was no net change in the mean visual field score. While $15 \%$ of such eyes were said to have worsened by four AGIS visual field units, an equal percentage 'improved' by the same criterion, perhaps providing an estimate of the false-positive rate of progression. In contrast, in those eyes in which the IOP was greater than $17 \mathrm{mmHg}$ more than half the time (average IOP, $20.2 \mathrm{mmHg}$ ), eyes lost an average of approximately three AGIS units during 8 years of follow-up. A clear dose-response relationship between IOP and risk of progressive field loss was evidenced for intermediate categories.

With surgery, levels of IOP in the low teens, or even lower, are technically achievable, ${ }^{20,21,34-37}$ and that is independent of the IOP values prior to surgery. What determines IOP levels postoperatively are mainly the degree of surgical precision intraoperatively, the resistance to outflow posed by the scleral flap in trabeculectomy, at least initially. In the long run, the degree of wound scarring ${ }^{30}$ postoperatively and whether this has been manipulated by antimetabolites, ${ }^{21,35}$ plays a role of paramount importance.

In topical medications, IOP in the low teens is less likely to be achieved, ${ }^{38}$ but nevertheless possible specially with newer classes of medications ${ }^{19}$ and with the use of combination topical medical therapies, while the level of IOP is largely dependent on IOP values before commencing therapy. Topical medications depending on their mechanisms of action, whether reducing production or increasing outflow, tend to knock down percentages of prior levels.

It is fair though to acknowledge that not every patient requires an IOP in the low teens in order to halt his glaucoma progression. In the collaborative initial glaucoma treatment study, ${ }^{24}$ it would seem that patients with mild, initial damage can do well at pressures in the mid-to-upper teens, while those with more advanced damage indeed do better when pressure is reduced to the lower teens.

\section{Long-term IOP reduction}

In spite of initial IOP reduction of some medications, the effect seems to ware off in many cases. Watson et al ${ }^{39}$ examined the long-term efficacy of monotherapy with topically applied beta-blocking agents. Analysis showed that less than half the eyes initially treated with topical beta blockers might be expected to still be being treated with their original medication after 5 years. The rest required either additional medication or trabeculectomy.

Long-term IOP reduction capabilities of other newer classes of medications are still not fully determined. ${ }^{40,41}$ One study ${ }^{19}$ with a 2-year follow-up found that Latanoprost significantly reduced IOP from pretreatment values, and this reduction was maintained over the 24-month treatment period with no sign of upward drift.

Surgery also shows deterioration of its results with time. Chen et $\mathrm{al}^{42}$ studied the long-term outcomes of primary trabeculectomies that were successful at 1 year. This was a retrospective study of patients with various types of glaucoma who had trabeculectomies that were successful at 1 year and who had a follow-up of at least 10 years. In all, 40 patients (40 eyes) were enrolled, who had primary trabeculectomies that were successful at 1 year and who had a follow-up range of 10-21 years. Control of IOP was evaluated at 5, 10, and 15 years and at the last obtainable follow-up. Successful control of IOP was defined as IOP less than $21 \mathrm{mmHg}$ or a reduction of $33 \%$ if preoperative IOP was less than $21 \mathrm{mmHg}$. Their results show that, if an eye was considered successful by IOP at 1 year, the probability of successful control of IOP was $82 \%$ at 5 years and $67 \%$ at 10 and 15 years. If an eye did not require further glaucoma surgery at 1 year, the probability that it would not still need further surgery at 5 years was $90 \%$, at 10 years $75 \%$, and at 15 years $67 \%$. They concluded that loss of IOP control and progression of glaucomatous damage occurs over time despite initial success at 1 year.

Another study ${ }^{43}$ examined the long-term results (1-14 years) of trabeculectomies with 5-fluorouracil injections that were successful at 1 year. In a retrospective 
noncomparative case series. The authors identified 87 patients (87 eyes) who had trabeculectomies with 5fluorouracil injections that were successful at 1 year and had a follow-up range of 1.0-14.7 years (mean 8.1, standard deviation of 4.4 years). All patients had previously failed glaucoma surgery $(66.7 \%)$, cataract surgery $(47.1 \%)$, or other diagnoses making them at high risk for failure. Successful control of IOP was defined as IOP less than $21 \mathrm{mmHg}$ or a reduction of $33 \%$ if preoperative pressure was less than $21 \mathrm{mmHg}$. Statistical analysis was performed using Kaplan-Meier life table analysis. If an eye is considered successful by IOP at 1 year, the probability of successful control is $61 \%$ at 5 years, $44 \%$ at 10 years, and $41 \%$ at 14 years. They concluded that, despite successful IOP control at 1 year, trabeculectomies with 5-fluorouracil injections show a continual loss of IOP control over time.

\section{Minimal IOP diurnal fluctuations}

Large diurnal fluctuations in IOP have been identified as an independent risk factor in patients with glaucoma. In a retrospective study of 114 patients under treatment for primary open-angle glaucoma (POAG) and ocular hypertension OHT over an 11-year period of observation, Niesel and Flammer ${ }^{44}$ described, more than a quarter of a century ago, a highly significant correlation between IOP and progression of visual field defects. This correlation could be shown for the visual field outer boundary in 81 eyes with OHT and for typical visual field defects in 33 eyes with chronic glaucoma. The relationship was, however, only significant when both the standard deviation of the annual IOP and the influence of cataract development upon visual acuity were considered. If only the mean IOP, not considering the standard deviation, is considered, this correlation is rendered insignificant. In another retrospective study ${ }^{45}$ by the same group they described clearly a significant correlation between concentric constriction during 11 years of observation and the IOP fluctuation.

Asrani et $a l^{46}$ have demonstrated that the diurnal IOP range and the IOP range over multiple days were significant risk factors for glaucomatous progression, even after adjusting for office IOP, age, race, gender, and visual field damage at baseline. This implies that we can no longer rely on an IOP in the statistically normal levels under treatment in office visits. Patients could still suffer from glaucomatous progression because of high fluctuations. What remains to be identified is the risk of this progression in large 'within statistically normal' fluctuations compared to fluctuations outside of what is statistically normal.

Migdal et $a l^{38}$ compared the long-term functional outcome in POAG in medically treated patients $v s$ surgically treated patients. Among many results from this study, they observed that patients in the surgerytreated group had the lowest mean IOPs and with fewer peaks and troughs. The maximum mean IOP was $15.5 \mathrm{mmHg}$ and the minimum mean IOP was $13.1 \mathrm{mmHg}$ for surgery, compared with 22.1 and $15.9 \mathrm{mmHg}$ for medicine.

Another study ${ }^{47}$ was designed specifically to compare the IOP fluctuations in glaucoma patients under ocular hypotensive therapy with those of patients previously submitted to trabeculectomy. IOP peaks and fluctuations for the same patients in response to the water-drinking test (WDT) were also examined. The study included 30 POAG patients using ocular hypotensive medications and with no history of previous intraocular surgery (medical group), and 30 POAG patients previously submitted to one or more trabeculectomies though taking no medication at the time of the study (surgical group). All patients were submitted to a diurnal tension curveDTC followed by the WDT. The IOP peak and IOP fluctuation during the diurnal tension curve were significantly greater in the medical group than in the surgical group. The same was observed following the WDT. From an overall baseline IOP of $10.6 \mathrm{mmHg}$, the mean IOP change following the WDT was $13 \%$ in the surgical group and $40 \%$ in the medical group. The study concluded that patients submitted to trabeculectomy have less IOP fluctuations during the diurnal tension curve and following a water-drinking provocative test.

This observation does constitute a definite advantage of surgery over medical treatment in that respect, thus potentially offering better potential chance of stabilisation or retardation of the glaucomatous disease process. One criticism to these two studies, though, was the inclusion of patients under different classes of ocular hypotensive medications under the medical group. Different classes have different effects on IOP diurnal curves, as has been demonstrated by Orzalesi et al ${ }^{48}$ They compared the around-the-clock IOP reduction induced by timolol $0.5 \%$, latanoprost $0.005 \%$, and dorzolamide in patients with POAG or OHT. This was a crossover trial, 20 patients with POAG or OHT were treated with timolol, latanoprost, and dorzolamide for 1 month. The treatment sequence was randomised. All patients underwent measurements for four 24-h tonometric curves: at baseline and after each 1-month period of treatment. The between-group differences were tested for significance by means of parametric analysis of variance. To compare the circadian IOP rhythms in the POAG-OHT and control groups, the acrophases for each subject were calculated. All the drugs significantly reduced IOP in comparison with baseline at all times, except for timolol at $0300 \mathrm{~h}$. Latanoprost was more effective in lowering IOP than timolol at 0300, 0600, and 
$0900 \mathrm{~h}(P=0.03)$, noon $(P=0.01), 2100 \mathrm{~h}$ and midnight $(P=0.05)$, and was more effective than dorzolamide at $0900 \mathrm{~h}$, noon $(P=0.03)$, and 1500 and $1800 \mathrm{~h}(P=0.04)$. Timolol was more effective than dorzolamide at $1500 \mathrm{~h}$ $(P=0.05)$, whereas dorzolamide performed better than timolol at midnight and $0300 \mathrm{~h}(P=0.05)$. In this study, Latanoprost seemed to lead to a fairly uniform circadian reduction in IOP, whereas timolol seemed to be less effective during the night-time hours. Dorzolamide was less effective than latanoprost, but led to a significant reduction in nocturnal IOP. Although the study compares the IOP-lowering effect of the medications over a diurnal curve, the study lacks, or does not report, information on the differences in fluctuations in the diurnal curve between the different medications. In fact, if one compares different diurnal curves of different medications, latanaprost seems to have its curve in the lowest level, but if one examines the IOP diurnal curves presented in this study, it appears that latanaprost provides a similar range of fluctuations to timolol. Another concern is that we are judging the mean IOPs and not individual curves, theoretically single individuals might be at a higher risk of glaucomatous progression due to high fluctuations, which would not be apparent from mean IOP curves, this is of special concern in an era where individualised therapeutic decisions are stressed.

Medication class-specific or even medication-specific studies comparing IOP fluctuations in surgically vs medically controlled glaucomatous patients are in dire need, if this point is to be resolved. Though, the bulk of evidence, for the time being, seems to point to a relative advantage of surgery over medications in that respect.

\section{The issue of compliance and persistence}

Though compliance is not a real issue in surgically treated patients, it does pose a serious challenge to the efficiency of medical treatment. ${ }^{49-55}$

Clinically significant noncompliance with glaucoma medications has been well documented. One study ${ }^{56}$ documented the prevalence of noncompliance in a Greek cohort. Clinically significant noncompliance (more than two doses missed per week) was established in $44 \%$ of patients examined. Men and those using eye drops more than four times a day were more likely to default.

Noncompliant patients exhibited higher mean IOP (22.9 vs $18.5 \mathrm{mmHg} ; P>0.001)$ and worse visual field loss (10.8 vs $7.0 \mathrm{~dB} ; P=0.008)$ compared with compliant patients. Involuntary non-compliance was also common in this group, with only $53 \%$ instilling their eye drops accurately.

Another study ${ }^{52}$ was designed to assess the levels of compliance in elderly glaucoma patients on timolol eye drops. In all, $24 \%$ of patients were admitted to omitting eye drops either occasionally or frequently. A total of $51 \%$ were found to have had insufficient drops dispensed to comply with treatment as prescribed. In noncomplaint patients, the mean period without drops was 85 days of the year, with a maximum of 165 days.

Compliance could theoretically, but safely, be assumed to be much worse in developing countries compared to developed countries, for obvious reasons. It could be assumed to improve with fewer medications and fewer doses per day, more easily tolerated side effects, as well as with better understanding of the nature and gravity of the disease process.

One study ${ }^{57}$ examined the causes of noncompliance with drug regimens in glaucoma patients. The results showed that forgetfulness was the number one reported reason for noncompliance.

In the literature, ${ }^{49-57}$ rates of noncompliance range between 23 and 51\%; whatever the rate may be in different communities and age groups, surgery has a clear advantage over medications in this respect.

One useful way in assessing compliance with eyedrop medications is the miniature compliance monitor, as purposed by Kass et al. ${ }^{58}$ The medication monitor resembles commercially available $30-\mathrm{ml}$ eyedrop bottles in size, shape, and weight. It electronically records the date and time of each medication administration over a 6-week period.

Glaucoma patients' persistence with long-term pharmacotherapy is also an issue of concern when discussing ocular hypotensive medications. Two studies ${ }^{59,60}$ have identified persistency as a significant factor that may influence not only health outcomes, but also long-term costs and health planning. One study compared the persistency (time on initial therapy) of latanoprost $v$ s beta-blocker monotherapy. The authors reported that patients receiving a beta-blocker as initial therapy were 3.8 times more likely to change therapy than those initially treated with latanoprost.

\section{Ocular side effects and complications}

Surgery carries with it a set of serious ocular side effects and complications, most notably endophthalmitis. ${ }^{61-64}$ The use of antimetabolites ${ }^{35,36,43,64-66}$ with trabeculectomy ups the stakes, on the one hand, better success rates are achieved, on the other higher complication rates are usually reported. Incidence of endophthalmitis is $0.2-1.5 \%{ }^{67,68}$ in trabeculectomies without antimetabolites (this should be compared to the incidence of endophthalmitis after cataract extraction, which ranges between 0.07 and $0.12 \%{ }^{69}$ ); in trabeculectomies with 5 -FU it is $3.0 \%^{70}$ and in trabeculectomies with MMC it is $2.1 \% .^{71}$ 
Another much dreaded, but fortunately a rare complication is expulsive haemorrhage. One study ${ }^{72}$ reported an incidence of $0.57 \%$ after trabeculectomy. Another study ${ }^{73}$ examined delayed suprachoroidal haemorrhage (DSCH) after glaucoma filtration procedures. Of a total of 1863 trabeculectomy procedures, DSCH developed in nine of 615 (1.5\%) trabeculectomies without antimetabolite, 30 of 1248 $(2.4 \%)$ trabeculectomies with antimetabolite.

Other complications that do occur more commonly include hypotonic maculopathy $(8.9 \%)$, bleb leaks (8-14.6\%), hyphaema (24.6\%), and choroidal detachment $(14.1 \%)^{74}$

Of special interest is cataract incidence after trabeculectomy. This complication, aside from its deleterious effect on vision, often necessitates another intraoperative surgery, which could adversely affect the initial trabeculectomy results. The cataractogenic effect of surgery has been well documented. ${ }^{24,75}$ Cataract incidence post trabeculectomy has been reported to be as high as $20.2 \%$ in a follow-up of 12 months. ${ }^{74}$

It is worth mentioning that such complication rates are not reported with nonpenetrating surgery. ${ }^{76-83}$ The vast majority of studies in the literature report significantly lower early postoperative complications compared to trabeculectomy. It also reports lower incidence of postoperative cataract formation. It is necessary though to acknowledge that the randomised controlled trials reporting on cataract incidence after nonpenetrating surgery do not have the same long-term follow-ups as in the case of trabeculectomy.

Ocular hypotensive medications are not devoid of ocular side effects and complications. For one, the early manifest glaucoma trial ${ }^{15}$ reported increases in clinical nuclear lens opacity gradings with medical treatment $(P=0.002)$. Similar observation, but not statistically significant, was observed in the ocular hypertensive treatment study, ${ }^{84}$ where $6.4 \%$ of the treatment group had cataract surgeries compared to $4.3 \%$ of the observation group $(P=0.06)$.

It is worth mentioning that the last two studies' medication groups were under different medications. We have no information about which ocular hypotensive medication would put a patient under a higher risk of cataract occurrence.

The noxious effect of ocular hypotensive medications on the ocular surface has been long identified. One study ${ }^{85}$ reported that administration of a single topical medication preserved with benzalkonium chloride, irrespective of type, for 3 months or more induced a significant degree of subclinical inflammation, detected as increased expression of HLA-DR on conjunctival epithelial cells. Another study ${ }^{86}$ reported that latanoprost treatment induces ocular surface changes which are more evident in POAG patients who are also affected by allergic conjunctivitis. The authors hypothesised that these findings are probably related to the very high latanoprost concentration of benzalkonium chloride and to its bedtime administration, which further amplifies the toxicity.

An increasing number of studies, ${ }^{24,38,87,88}$ both experimental and epidemiological, have provided evidence that filtering glaucoma surgery may be less effective than initially described. Of a number of risk factors for failure, duration and number of antiglaucoma drugs prior to surgery seem to play a critical role and highly accumulated antiglaucoma topical treatments significantly reduce the success rates. ${ }^{89}$ Inversely, trabeculectomies performed as a primary procedure do offer higher success rates than trabeculectomies performed after a history of ocular hypotensive medications.

Again, very little is known about which medication, in which patient is associated with which adverse effects, and if that is clinically relevant.

\section{Systemic side effects and complications}

Aside from the systemic side effects of general anaesthesia, which is rarely resorted to in glaucoma surgery ${ }^{90-92}$ nowadays, surgery appears to be at a clear advantage in this respect. Ocular hypotensive medications have a long list of potential systemic side effects $^{93-96}$ (Table 1).

Among others, pulmonary effects of beta-blockers are exceptionally worrisome. Two drops of $0.5 \%$ timolol equates to a $10 \mathrm{mg}$ oral dose. This is not enough to cause symptoms in many patients, but unfortunately glaucoma and airways disease frequently coexist. Glaucoma affects $5 \%$ of people over 65 years $^{97}$ and incidence ${ }^{98}$ of asthma in elderly patients (above 65 years old) is $4 \%$ in males and $7 \%$ in females. This should not be understood in the sense that beta-blockers are contraindicated in patients above 65 years, only patients with a clinically relevant bronchial asthma does run a risk with beta-blockers.

Attempts have been made though to offer better safety profile ocular hypotensive medications. Betaxolol (Betoptic) is a cardioselective beta-blocker, but is associated with poorer IOP control. ${ }^{99}$ Carbonic anhydrase inhibitors ${ }^{31,48,100-106}$ applied topically are associated with less serious systemic side effects, but are also less potent than if orally administered.

Prostaglandins ${ }^{19,41,48,96}$ are, however, very effective at lowering the IOP with, as far as we know, minimal systemic side effects, and have become the treatment of first choice in many cases.

The advantage of beta blockers, still, is that it has been tried and tested, we know a lot about beta-blockers and 
Table 1 Side effects of ocular hypotensive medications

\begin{tabular}{|c|c|c|c|c|c|}
\hline Medication & B Blockers & $\begin{array}{l}\text { Carbonic Anhydrase } \\
\text { Inhibitors (oral and } \\
\text { topical) }\end{array}$ & Alpha Agonists & $\begin{array}{l}\text { Parasympatho } \\
\text { mimetics }\end{array}$ & $\begin{array}{l}\text { Prostaglandin } \\
\text { analogues }\end{array}$ \\
\hline Side effects & $\begin{array}{l}\text { Dyspnea, } \\
\text { Bradycardia } \\
\text { impotence } \\
\text { confusion, } \\
\text { depression, } \\
\text { hypotension } \\
\text { wrsening of } \\
\text { peripheral vascular } \\
\text { disease }\end{array}$ & $\begin{array}{l}\text { Parasthesiae (systemic) } \\
\text { Renal Stones (systemic) } \\
\text { Blood dyscrasias (systemic } \\
\text { and ? topical Rashes } \\
\text { (either) Hypokalaemia } \\
\text { (systemic) Polyuria } \\
\text { (systemic) Metallic taste } \\
\text { (topical and systemic) }\end{array}$ & $\begin{array}{l}\text { Dry mouth GI upset } \\
\text { palpitations fatigue } \\
\text { decreased libido, } \\
\text { hypotension } \\
\text { rspiratory arrest in } \\
\text { infants }\end{array}$ & $\begin{array}{l}\text { Nausea Vomiting } \\
\text { Headache } \\
\text { Confusion }\end{array}$ & $\begin{array}{l}\text { Minimal systemic } \\
\text { side effects caution } \\
\text { in asthma? } \\
\text { contrainicated in } \\
\text { pregnancy }\end{array}$ \\
\hline
\end{tabular}

we probably do not know the same amount of information about newer classes of ocular hypotensive medications. This makes beta-blockers still a very valid option.

\section{Economical burden of IOP-lowering strategies}

The cost of surgical reduction of IOP decreases with time, where the cost of surgery can be divided by the number of years of life expectancy. The opposite is true for ocular hypotensive medications where the cost increases with time and could be multiplied by the number of years of life expectancy.

The cost of medication ${ }^{107,108}$ for a latanaprost-treated patient per year is $337 \$$, while it is $336 \$$ and $288 \$$ for betaxolol and dorzolamide, respectively. The daily cost of latanaprost is $0.87 \$$; this should be put in context with the fact that, according to the United Nations and the World Bank, more than one billion to 1.3 billion people live on a daily income of less than $1 \$$ (one dollar) a day. This makes glaucoma a surgical disease in most of the developing countries. Developing countries have the majority of glaucoma patents, and thus surgery is the treatment of choice to the majority of glaucoma patients. Unfortunately, very little industry research funding is being allocated for research in glaucoma surgery, which the majority of glaucoma patients are poised to benefit from.

There is evident lack of studies related to economic evaluation in glaucoma. Kobelt ${ }^{109}$ states that the genuine lack of a useful outcome measure, and the impossibility to calculate the absolute annual risk of vision loss at given levels of the one parameter that is being treated, IOP, has essentially limited the research to resource utilisation. Another limitation is that economical studies usually take in consideration data from industrialised countries, which could be misleading if applied to developing countries' circumstances.

\section{Conclusions}

In essence, surgery has the potential to fulfil many features of an ideal approach to reduce IOP over drugs. It can lower the IOP to low teens, achieve long-term IOP reduction, minimise IOP fluctuations, lower the cost, and minimise systemic side effects. The major drawback, though, is the potentially devastating, but rare, ocular side effects.

Although surgery is usually the first-line treatment in developing countries, it is still resorted to as a final attempt to reduce IOP in developed countries. The possibility of employing surgery as a first-line treatment is limited by the high incidence of potential ocular complications.

Beta-blockers are effective and relatively safe ocular hypotensive medications, but have a well-established list of side effects; it has been tried and tested over long-term follow-ups. The real advantage lies in the fact that the amount of information that we possess about betablockers is relatively large. Prostaglandins may offer certain advantages of limited side effects and effective IOP reduction, but longer follow-ups are in dire need to provide evidence of efficacy and safety.

There is evidence that nonpenetrating surgery could offer a safer option to trabeculectomy, but the widespread practice is hindered by its surgical complexity, which results in long learning curves. Being technically demanding, it is very difficult to employ in mass surgical treatment, specially in developing countries. The use of implants with nonpenetrating surgery is an extra considerable cost. Another disadvantage is that nonpenetrating surgery does not seem to achieve its previously defined target IOP, in a significant percentage, without the postoperative use of goniopuncturing, which necessitates the access to laser equipment. ${ }^{110}$

There is an urgent need to improve our surgical options in order to reduce the related ocular 
complications. If possible, safer and simpler surgical procedures should be developed to tackle the bulk of our glaucoma problem in developing countries.

Reducing IOP, is surgery better than drugs? As is the case in many aspects of glaucoma, indeed as in life itself, there are no easy answers to such questions. What could be at a clear advantage for one patient could be an absolute contraindication for another. In fact, many patients, specially in the developing world, do not have the luxury of an option.

We look forward to the day when effectively reducing IOP would not be such an important matter, when we can manipulate other risk factors, such as vascular autoregulation and neuronal damage, to the advantage of our glaucoma patients.

\section{References}

1 Anderson DR. Glaucoma: the damage caused by pressure. XLVI Edward Jackson memorial lecture. Am J Ophthalmol 1989; 108: 485-495.

2 Bathija R, Gupta N, Zangwill L, Weinreb RN. Changing definition of glaucoma. J Glaucoma 1998; 7: 165-169.

3 Foster PJ, Buhrmann R, Quigley HA, Johnson GJ. The definition and classification of glaucoma in prevalence surveys. Br J Ophthalmol 2002; 86: 238-242.

4 Munoz B, West SK, Rubin GS, Schein OD, Quigley HA, Bressler SB et al. Causes of blindness and visual impairment in a population of older Americans: The Salisbury Eye Evaluation Study. Arch Ophthalmol 2000; 118: 819-825.

5 Quigley HA, Vitale S. Models of open-angle glaucoma prevalence and incidence in the United States. Invest Ophthalmol Vis Sci 1997; 38: 83-91.

6 Quigley HA. Proportion of those with open-angle glaucoma who become blind. Ophthalmology 1999; 106: 2039-2041.

7 Buckley C, Hadoke PW, Henry E, O'Brien C. Systemic vascular endothelial cell dysfunction in normal pressure glaucoma. Br J Ophthalmol 2002; 86: 227-232.

8 Gasser P. Why study vascular factors in glaucoma? Int Ophthalmol 1998; 22: 221-225.

9 Haefliger IO, Dettmann E, Liu R, Meyer P, Prunte C, Messerli J et al. Potential role of nitric oxide and endothelin in the pathogenesis of glaucoma. Surv Ophthalmol 1999; 43(Suppl 1): S51-S58.

10 Leske MC, Heijl A, Hussein M, Bengtsson B, Hyman L, Komaroff E. Factors for glaucoma progression and the effect of treatment: the early manifest glaucoma trial. Arch Ophthalmol 2003; 121: 48-56.

11 Osborne NN, Chidlow G, Nash MS, Wood JP. The potential of neuroprotection in glaucoma treatment. Curr Opin Ophthalmol 1999; 10: 82-92.

12 Palmberg P. Risk factors for glaucoma progression: Where does intraocular pressure fit in? Arch Ophthalmol 2001; 119: 897-898.

13 Ritch R. Exfoliation syndrome. Curr Opin Ophthalmol 2001; 12: $124-130$.
14 Soltau JB, Zimmerman TJ. Changing paradigms in the medical treatment of glaucoma. Surv Ophthalmol 2002; 47 (Suppl): S2-S5.

15 Leske MC, Heijl A, Hussein M, Bengtsson B, Hyman L, Komaroff E. Factors for glaucoma progression and the effect of treatment: the early manifest glaucoma trail. Arch Ophthalmol 2003; 121(1): 48-56.

16 Leske MC, Heijl A, Hussein M, Bengtsson B, Hyman L, Komaroff E. Factors for glaucoma progression and the effect of treatment: the early manifest glaucoma trial. Arch Ophthalmol 2003; 121: 48-56.

17 Collaborative Normal-Tension Glaucoma Study Group. The effectiveness of intraocular pressure reduction in the treatment of normal-tension glaucoma. Am J Ophthalmol 1998; 126: 498-505.

18 Bron A. Treatment of glaucomas. Rev Prat 2001; 51: 2198-2201.

19 Hedman K, Watson PG, Alm A. The effect of latanoprost on intraocular pressure during 2 years of treatment. Surv Ophthalmol 2002; 47 (Suppl 1): S65-S76.

20 Rothman RF, Liebmann JM, Ritch R. Low-dose 5fluorouracil trabeculectomy as initial surgery in uncomplicated glaucoma: long-term followup. Ophthalmology 2000; 107 (Suppl 6): 1184-1190.

21 Uchida S, Suzuki Y, Araie M, Shigeeda T, Hara T, Shirato S. Long-term follow-up of initial 5-fluorouracil trabeculectomy in primary open-angle glaucoma in Japanese patients. J Glaucoma 2001; 10 (Suppl 6): 458-465.

22 Wilensky JT. The role of medical therapy in the rank order of glaucoma treatment. Curr Opin Ophthalmol 1999; 10: 109-111.

23 Shaarawy T. Surgery for glaucoma in the 21st century. $\mathrm{Br} \mathrm{J}$ Ophthalmol 2003; 87: 250.

24 Janz NK, Wren PA, Lichter PR, Musch DC, Gillespie BW, Guire KE et al. The Collaborative Initial Glaucoma Treatment Study: interim quality of life findings after initial medical or surgical treatment of glaucoma. Ophthalmology 2001; 108: 1954-1965.

25 Ritch R. Initial treatment of exfoliative glaucoma. J Glaucoma 1998; 7: 137-140.

26 Hitchings R. Initial treatment for open-angle glaucoma-medical, laser, or surgical? Surgery is the treatment of choice for open-angle glaucoma. Arch Ophthalmol 1998; 116: 241-242.

27 Jampel HD. Initial treatment for open-angle glaucoma - medical, laser, or surgical? Laser trabeculoplasty is the treatment of choice for chronic open-angle glaucoma. Arch Ophthalmol 1998; 116: 240-241.

28 Higginbotham EJ. Initial treatment for open-angle glaucoma-medical, laser or surgical? Medication is the treatment of choice for chronic open-angle glaucoma. Arch Ophthalmol 1998; 116: 239-240.

29 Pliushko DG. Drug treatment of the initial stage of glaucoma. Oftalmol Zh 1981; 36: 4-8.

30 Khaw PT, Cordeiro MF, Cordiero MF. Towards better treatment of glaucoma. Br Med J 2000; 320: 1619-1620.

31 Rouland JF, Le Pen C, Gouveia PC, Berto P, Berdeaux G. Cost-minimisation study of dorzolamide versus brinzolamide in the treatment of ocular hypertension and primary open-angle glaucoma: in four European countries. Pharmacoeconomics 2003; 21: 201-213.

32 Ogawa T, Ogawa A, So K. Target intraocular pressure and risk factors for progression of visual field loss in primary 
open-angle glaucoma. Nippon Ganka Gakkai Zasshi 2002; 106: 488-493.

33 The Advanced Glaucoma Intervention Study (AGIS): 7. The relationship between control of intraocular pressure and visual field deterioration. The AGIS Investigators. Am J Ophthalmol 2000; 130: 429-440.

34 Briggs MC, Jay JL. Age over 46 years does not affect the pressure lowering effect of trabeculectomy in primary open angle glaucoma. Br J Ophthalmol 1999; 83: 280-284

35 Ustundag C, Diestelhorst M. Effect of mitomycin C on aqueous humor flow, flare and intraocular pressure in eyes with glaucoma 2 years after trabeculectomy. Graefes Arch Clin Exp Ophthalmol 1998; 236: 734-738.

36 Wilson RP, Steinmann WC. Use of trabeculectomy with postoperative 5-fluorouracil in patients requiring extremely low intraocular pressure levels to limit further glaucoma progression. Ophthalmology 1991; 98: 1047-1052.

37 Saiz A, Alcuaz A, Maquet JA, de la Fuente F. Pressurecurve variations after trabeculectomy for chronic primary open-angle glaucoma. Ophthalmic Surg 1990; 21 (Suppl 11): 799-801.

38 Migdal C, Gregory W, Hitchings R. Long-term functional outcome after early surgery compared with laser and medicine in open-angle glaucoma. Ophthalmology 1994; 101: 1651-1656.

39 Watson PG, Barnett MF, Parker V, Haybittle J. A 7 year prospective comparative study of three topical beta blockers in the management of primary open angle glaucoma. Br J Ophthalmol 2001; 85: 962-968.

40 Watson PG. Latanoprost. Two years' experience of its use in the United Kingdom. Latanoprost Study Group. Ophthalmology 1998; 105: 82-87.

41 Alm A, Camras CB, Watson PG. Phase III latanoprost studies in Scandinavia, the United Kingdom and the United States. Surv Ophthalmol 1997; 41(Suppl 2): S105-S110.

42 Chen TC, Wilensky JT, Viana MA. Long-term follow-up of initially successful trabeculectomy. Ophthalmology 1997; 104: 1120-1125.

43 Suzuki R, Dickens CJ, Iwach AG, Hoskins Jr HD, Hetherington Jr J, Juster RP et al. Long-term follow-up of initially successful trabeculectomy with 5-fluorouracil injections. Ophthalmology 2002; 109: 1921-1924.

44 Niesel P, Flammer J. Correlations between intraocular pressure, visual field and visual acuity, based on 11 years of observations of treated chronic glaucomas. Int Ophthalmol 1980; 3: 31-35.

45 Flammer J, Eppler E, Niesel P. Quantitative perimetry in the glaucoma patient without local visual field defects. Graefes Arch Clin Exp Ophthalmol 1982; 219: 92-94.

46 Asrani S, Zeimer R, Wilensky J, Gieser D, Vitale S, Lindenmuth $\mathrm{K}$. Large diurnal fluctuations in intraocular pressure are an independent risk factor in patients with glaucoma. J Glaucoma 2000; 9: 134-142.

47 Medeiros FA, Pinheiro A, Moura FC, Leal BC, Susanna R Jr. Intraocular pressure fluctuations in medical versus surgically treated glaucomatous patients. J Ocul Pharmacol Ther 2002; 18: 489-498.

48 Orzalesi N, Rossetti I, Bottoli A, Invernizzi T, Fumagalli E, Fogagnolo P. Comparison of latanoprost, brimonidine and a fixed combination of timolol and dorzolamide on circadian intraocular pressure in patients with primary open-angle glaucoma and ocular hypertension. Acta Ophthalmol Scand Suppl 2002; 236: 55.
49 Norell S. Medication behaviour. A study of outpatients treated with pilocarpine eye drops for primary open-angle glaucoma. Acta Ophthalmol Suppl 1980; (Suppl 143): 1-28.

50 Norell SE. Improving medication compliance: a randomised clinical trial. Br Med J 1979; 2: 1031-1033.

51 Kosoko O, Quigley HA, Vitale S, Enger C, Kerrigan L, Tielsch JM. Risk factors for noncompliance with glaucoma follow-up visits in a residents' eye clinic. Ophthalmology 1998; 105: 2105-2111.

52 Rotchford AP, Murphy KM. Compliance with timolol treatment in glaucoma. Eye 1998; 12(Part 2): 234-236.

53 Fingeret $\mathrm{M}$, Schuettenberg SP. Patient drug schedules and compliance. J Am Optom Assoc 1991; 62: 478-480.

54 Granstrom PA. Progression of visual field defects in glaucoma. Relation to compliance with pilocarpine therapy. Arch Ophthalmol 1985; 103: 529-531.

55 Norell SE. Improving medication compliance: a randomised clinical trial. Br Med J 1979; 2: 1031-1033.

56 Konstas AG, Maskaleris G, Gratsonidis S, Sardelli C. Compliance and viewpoint of glaucoma patients in Greece. Eye 2000; 14(Part 5): 752-756.

57 Patel SC, Spaeth GL. Compliance in patients prescribed eyedrops for glaucoma. Ophthalmic Surg 1995; 26: 233-236.

58 Kass M, Meltzer D, Gordon M. A miniature compliance monitor for eyedrop medication. Arch Ophthalmol 1984; 102: $1550-1554$

59 Reardon G, Schwartz G, Mozaffari E, e. Patient persistency with pharmacotherapy in the management of glaucoma. Eur J Ophthalmol 2003; 13(Suppl 4): 52.

60 Diestelhorst M, Schaefer C, Beusterien K, Plante K, Fain J, Mozaffari E et al. Persistency and clinical outcomes associated with latanoprost and beta-blocker monotherapy: evidence from a European retrospective cohort study. Eur J Ophthalmol 2003; 13(Suppl 4): S21-9.

61 Beck AD, Grossniklaus HE, Hubbard B, Saperstein D, Haupert CL, Margo CE. Pathologic findings in late endophthalmitis after glaucoma filtering surgery. Ophthalmology 2000; 107: 2111-2114.

62 Freedman J, Gupta M, Bunke A. Endophthalmitis after trabeculectomy. Arch Ophthalmol 1978; 96: 1017-1018.

63 Krzystolik MG, Ciulla TA, Topping TM, Baker AS. Exogenous Aspergillus niger endophthalmitis in a patient with a filtering bleb. Retina 1997; 17: 461-462.

64 Higginbotham EJ, Stevens RK, Musch DC, Karp KO, Lichter PR, Bergstrom TJ et al. Bleb-related endophthalmitis after trabeculectomy with mitomycin C. Ophthalmology 1996; 103: 650-656.

65 Freedman SF, McCormick K, Cox TA. Mitomycin Caugmented trabeculectomy with postoperative wound modulation in pediatric glaucoma. J AAPOS 1999; 3: 117-124.

66 Mandal AK, Bagga H, Nutheti R, Gothwal VK, Nanda AK. Trabeculectomy with or without mitomycin-C for paediatric glaucoma in aphakia and pseudophakia following congenital cataract surgery. Eye 2003; 17: 53-62.

67 Azuara-Blanco A, Katz LJ. Dysfunctional filtering blebs. SurvOphthalmol 1998; 43: 93-126.

68 Ayyala RS, Bellows AR, Thomas JV, Hutchinson BT. Bleb infections: clinically different courses of 'blebitis' and endophthalmitis. Ophthalmic Surg Lasers 1997; 28: 452-460.

69 Kresloff MS, Castellarin AA, Zarbin MA. Endophthalmitis. Surv Ophthalmol 1998; 43: 193-224.

70 Wolner B, Liebmann JM, Sassani JW, Ritch R, Speaker M, Marmor M. Late bleb-related endophthalmitis after 
trabeculectomy with adjunctive 5-fluorouracil. Ophthalmology 1991; 98: 1053-1060.

71 Greenfield DS, Suner IJ, Miller MP, Kangas TA, Palmberg PF, Flynn HW, Jr. Endophthalmitis after filtering surgery with mitomycin. Arch Ophthalmol 1996; 114: 943-949.

72 Ishida M, Takeuchi S. Vitrectomy for the treatment of expulsive hemorrhage. Jpn J Ophthalmol 2000; 44: 571.

73 Tuli SS, WuDunn D, Ciulla TA, Cantor LB. Delayed suprachoroidal hemorrhage after glaucoma filtration procedures. Ophthalmology 2001; 108: 1808-1811.

74 Edmunds B, Thompson JR, Salmon JF, Wormald RP. The National Survey of Trabeculectomy. III. Early and late complications. Eye 2002; 16: 297-303.

75 Anderson D. Normal tension glaucoma study. Collaborative normal tension glaucoma study. Curr Opin Ophthalmol 2003; 14: 86-90.

76 Shaarawy T, Karlen M, Schnyder C, Achache F, Sanchez E, Mermoud A. Five-year results of deep sclerectomy with collagen implant. J Cataract Refract Surg 2001; 27: 1770-1778.

77 Ambresin A, Borruat FX, Mermoud A. Recurrent transient visual loss after deep sclerectomy. Arch Ophthalmol 2001; 119: 1213-1215.

78 Chiselita D. Non-penetrating deep sclerectomy versus trabeculectomy in primary open- angle glaucoma surgery. Eye 2001; 15: 197-201.

79 El Sayyad F, Helal M, El-Kholify H, Khalil M, El-Maghraby A. Nonpenetrating deep sclerectomy versus trabeculectomy in bilateral primary open-angle glaucoma. Ophthalmology 2000; 107: 1671-1674.

80 Gandolfi S, Cimino L. Deep sclerectomy without absorbable implants and with unsutured scleral flap: prospective, randomized 2-year clinical trial vs trabeculectomy with releasable sutures. Conference Proceedings. Fort Lauderdale, USA, 2000.

81 Mermoud A, Schnyder CC, Sickenberg M, Chiou AG, Hediguer SE, Faggioni R. Comparison of deep sclerectomy with collagen implant and trabeculectomy in open-angle glaucoma. J Cataract Refract Surg 1999; 25: 323-331.

82 Carassa R. Viscocanalaostomy versus trabeculectomy: a 12 months prospective randomized study. Conference Proceedings. Boston, USA, 2000.

83 O'Brart DP, Rowlands E, Islam N, Noury AM. A randomised, prospective study comparing trabeculectomy augmented with antimetabolites with a viscocanalostomy technique for the management of open angle glaucoma uncontrolled by medical therapy. Br J Ophthalmol 2002; 86: 748-754.

84 Gordon MO, Beiser JA, Brandt JD, Heuer DK, Higginbotham EJ, Johnson CA et al. The Ocular Hypertension Treatment Study: baseline factors that predict the onset of primary open-angle glaucoma. Arch Ophthalmol 2002; 120: 714-720.

85 Cvenkel B, Ihan A. Ocular surface changes induced by topical antiglaucoma monotherapy. Ophthalmologica 2002; 216: $175-179$.

86 Costagliola C, Prete AD, Incorvaia C, Fusco R, Parmeggiani F, Di Giovanni A. Ocular surface changes induced by topical application of latanoprost and timolol: a short-term study in glaucomatous patients with and without allergic conjunctivitis. Graefes Arch Clin Exp Ophthalmol 2001; 239: 809-814.

87 Watson PG, Jakeman C, Ozturk M. The complications of trabeculectomy (a 20-year follow-up). Eye 1990; 4: 425-438.
88 Molteno A, Bosma N, Kittelson J. Otago glaucoma surgery outcome study: long-term results of trabeculectomy-1976 to 1995. Ophthalmology 2003; 106: 1742-1750.

89 Broadway D, Grierson I, O'Brien C, Hitchings R. Adverse effects of topical antiglaucoma medications. II. The outcome of filtration surgery. Arch Ophthalmol 1994; 112: 1446-1454.

90 Kansal S, Moster MR, Gomes MC, Schmidt Jr CM, Wilson RP. Patient comfort with combined anterior sub-Tenon's, topical, and intracameral anesthesia versus retrobulbar anesthesia in trabeculectomy, phacotrabeculectomy, and aqueous shunt surgery. Ophthalmic Surg Lasers 2002; 33: $456-462$.

91 Sauder G, Jonas JB. Topical anesthesia for penetrating trabeculectomy. Graefes Arch Clin Exp Ophthalmol 2002; 240: 739-742.

92 Vicary D, McLennan S, Sun XY. Topical plus subconjunctival anesthesia for phacotrabeculectomy: one year follow-up. J Cataract Refract Surg 1998; 24: 1247-1251.

93 Farrell TA. Minimizing the systemic effects of glaucoma medications. Geriatrics 1991; 46, 61-64, 73.

94 Fraunfelder FT, Meyer SM. Systemic side effects from ophthalmic timolol and their prevention. J Ocul Pharmacol 1987; 3: 177-184.

95 Bourgeois JA. Depression and topical ophthalmic beta adrenergic blockade. J Am Optom Assoc 1991; 62: 403-406.

96 Waldock A, Snape J, Graham CM. Effects of glaucoma medications on the cardiorespiratory and intraocular pressure status of newly diagnosed glaucoma patients. $\mathrm{Br} \mathrm{J}$ Ophthalmol 2000; 84: 710-713.

97 Leibowitz HM, Krueger DE, Maunder LR, Milton RC, Kini MM, Kahn HA et al. The Framingham Eye Study monograph: an ophthalmological and epidemiological study of cataract, glaucoma, diabetic retinopathy, macular degeneration, and visual acuity in a general population of 2631 adults, 1973-1975. Surv Ophthalmol 1980; 24: 335-610.

98 Burrows B, Barbee RA, Cline MG, Knudson RJ, Lebowitz MD. Characteristics of asthma among elderly adults in a sample of the general population. Chest 1991; 100: 935-942.

99 Kaiser HJ, Flammer J, Stumpfig D, Hendrickson P. Longterm visual field follow-up of glaucoma patients treated with beta- blockers. Surv Ophthalmol 1994; 38(Suppl): S156-S159.

100 Orzalesi N, Rossetti I, Bottoli A, Invernizzi T, Fumagalli E, Fogagnolo P. Comparison of latanoprost, brimonidine and a fixed combination of timolol and dorzolamide on circadian intraocular pressure in patients with primary open-angle glaucoma and ocular hypertension. Acta Ophthalmol Scand Suppl 2002; 236: 55.

101 Arieta C, Amaral M, Matuda E, Crosta C, Carvalho Moreira FD, Jose N. Dorzolamide x Apraclonidine in the prevention of the intraocular pressure spike after Nd:YAG laser posterior capsulotomy. Curr Eye Res 2002; 25: 237-241.

102 Day DG, Schacknow PN, Wand M, Sharpe ED, Stewart JA, Leech $\mathrm{J}$ et al. Timolol 0.5\%/dorzolamide $2 \%$ fixed combination vs timolol maleate $0.5 \%$ and unoprostone $0.15 \%$ given twice daily to patients with primary openangle glaucoma or ocular hypertension. Am J Ophthalmol 2003; 135: 138-143.

103 Honrubia FM, Larsson LI, Spiegel D. A comparison of the effects on intraocular pressure of latanoprost $0.005 \%$ and the fixed combination of dorzolamide $2 \%$ and timolol $0.5 \%$ in patients with open-angle glaucoma. Acta Ophthalmol Scand 2002; 80: 635-641. 
104 Simmons ST. Efficacy of brimonidine $0.2 \%$ and dorzolamide $2 \%$ as adjunctive therapy to beta-blockers in adult patients with glaucoma or ocular hypertension. Clin Ther 2001; 23: 604-619.

105 Strohmaier K, Snyder E, DuBiner H, Adamsons I. The efficacy and safety of the dorzolamide-timolol combination versus the concomitant administration of its components. Dorzolamide-Timolol Study Group. Ophthalmology 1998; 105: 1936-1944.

106 Strahlman E, Tipping R, Vogel R. A six-week dose-response study of the ocular hypotensive effect of dorzolamide with a one-year extension. Dorzolamide Dose-Response Study Group. Am J Ophthalmol 1996; 22(2): 183-194.
107 Vold SD, Riggs WL, Jackimiec J. Cost analysis of glaucoma medications: a 3-year review. J Glaucoma 2002; 11: 354-358.

108 Vold SD, Wiggins DA, Jackimiec J. Cost analysis of glaucoma medications. J Glaucoma 2000; 9: 150-153.

109 Kobelt G. Health economics, economic evaluation, and glaucoma. J Glaucoma 2003; 11: 531-539.

110 Gandolfi S, Quaranta L, Cimino L, Bettelli S. Deep sclerectomy versus trabeculectomy. Prospective Randomized Clinical trial. 4-year interim analysis. Proceedings of the Second International Congress on Glaucoma Surgery. Luxor, Egypt, 2003. 